\title{
Short Note \\ Effects of fertilizer application on fruiting-yield of Jatropha curcas Linn.
}

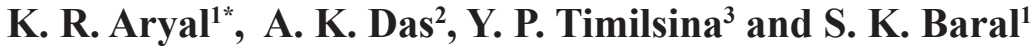

$\mathrm{S}$ ajiwan (Jatropha curcas Linn.) is one of the widely used plant species for bio-fuel production. It is a drought-resistant shrub or tree belonging to the family Euphorbiaceae, which is cultivated in Central, and South America, Southeast Asia, India and Africa (MartınezHerrera et al., 2006). It can also grow out to the size of a tree as large as $12 \mathrm{~m}$ high (Sirisomboona et al., 2007). The plant is believed to be a native of South America and Africa but later distributed to other continents of the world by the Portuguese settlers (Gubitz et al., 1999). Katwal and Soni (2003) described that it is able to thrive in a number of climatic zones with rainfall ranging from $250 \mathrm{~mm}$ to $1200 \mathrm{~mm}$. In Nepal, it is found in all districts of Terai, Mid-hills, and low lying areas of mountains.

The fruits of Sajiwan are used to produce biofuel. It reaches its maximum productivity in five years, and can live up to 50 years (Sirisomboona et al., 2007). It has been reported that the dry seed of Sajiwan would yield about $30-38 \%$ of crude oil using an engine-driven expeller (Forson et al., 2004). Acceptable thermal efficiencies of the engine are obtained with blends containing up to 50 per cent volume of Sajiwan oil (Pramanik, 2003). Multiple benefits of Sajiwan plants are not only useful in saving environmental pollution but also supports for employment generation and entrepreneurship developments.

Some studies have been carried out on raising the fruiting-yield of Sajiwan in the world. For example, pruning (Beckford, 2008) and application of chemical fertilizers (Yong et al., 2010; Ghosh et al., 2011) can increase the fruitingyield while maintaining the same intrinsic seed-oil content, but in Nepal, limited studies have been conducted on Sajiwan, and they only deal with the socio-economic aspect of Sajiwan plantation (eg. Parajuli, 2010; Ranabhat, 2009). Meanwhile, Nepalese farmers are suffering from the poor fruiting-yield of Sajiwan. We still do not know the true factor that limits the fruiting-yield of Sajiwan in Nepal. In this context, we hypothesize that the fruiting-yield of Sajiwan in Nepal is limited due to the status of poor soil-nutrient contents. To test this hypothesis, this study was designed and different treatments (types of fertilizer) were applied in a site where the planting materials were from two different origins (i.e. seeds and branch cuttings).

\section{Materials and methods}

\section{Study area}

The trial was conducted within eight-year-old plantation of Sajiwan located at Khairenitar Village Development Committee (VDC) of Tanahun District of Nepal. The site covers 45 hectares of the land under which only 22 hectares was cultivated with Sajiwan in 2003. The elevation of the site ranges from $501 \mathrm{~m}$ to 505 $m$ above mean sea level, and exhibits subtropical type of climate.

\section{Soil characteristics of the site}

Three points were selected randomly from the entire plantation site. Soil samples were collected from three different depths $(0-10 \mathrm{~cm}, 10-20 \mathrm{~cm}$ and $20-30 \mathrm{~cm}$ ) from the ground surface in each point. Soil analysis was carried out at soil test centre (lab), Pokhara.

\section{Design of experiment and treatment application}

The experiment was designed as two blocks of different planting materials (seedlings and branch cuttings), with seven replications of

Department of Forest Research and Survey, Kathmandu, Nepal

2 Nepal Foresters Association, Kathmandu, Nepal

3 Institute of Forestry, Pokhara, Nepal

* Corresponding author: E-mail: kamalrajaryal2003@gmail.com 
$10 \mathrm{~m} \times 10 \mathrm{~m}$ plots with three different treatments (control, compost, and chemical fertilizers). The trial plot was established in April 2008. Twenty $\mathrm{kg}$ of compost was applied to each plant in April for two years. A dose of chemical fertilizers consisting of $300 \mathrm{gm}$ potassium $\left(\mathrm{K}_{2} \mathrm{O}\right), 350 \mathrm{gm}$ Urea, $250 \mathrm{gm}$ phosphorus $\left(\mathrm{P}_{2} \mathrm{O}_{5}, \mathrm{DAP}\right), 30 \mathrm{gm}$ Boron and $30 \mathrm{gm}$ Zinc was applied to each plant as a treatment of chemical fertilizers. Insecticides were sprayed uniformly to all blocks before flowering and fruiting to protect from insect damage.

\section{Data collection and analysis}

One row was selected randomly in each plot. Counting of fruits was done in each plant on the selected rows in July 2010. Two-way ANOVA was used to test whether there was significant difference in the average fruiting yields between blocks (seedling and branch cutting) and among treatments (control, compost, chemical fertilizer) at 5\% level of significance. Multiple comparisons (LSD test) were done to find out the best treatment type.

\section{Results and discussion}

\section{Soil features}

The soil in the research site was found to be very poor in nutrient contents, and was alkaline i.e. $\mathrm{pH}$ 7.81 . Nitrogen content in the top layer up to $10 \mathrm{~cm}$ was found to be high whereas potassium, boron and zinc were low (Table 1). The constituents of the chemical nutrients in the soil were: $2.51 \%$ organic matter, $0.12 \%$ available nitrogen, 48.78 $\mathrm{kg} / \mathrm{ha}$ available phosphorus $\left(\mathrm{P}_{2} \mathrm{O}_{5}\right), 889.78 \mathrm{~kg} /$ ha available calcium, $17.56 \mathrm{~kg} / \mathrm{ha}$ available potassium $\left(\mathrm{K}_{2} \mathrm{O}\right), 0.46 \mathrm{ppm}$ available boron, and $0.35 \mathrm{ppm}$ available zinc.

Table 1: Soil characteristics

\begin{tabular}{llll}
\hline Parameter & $\begin{array}{l}\text { Soil depth: } \\
(\mathbf{0}-\mathbf{1 0} \mathbf{c m})\end{array}$ & $\begin{array}{l}\text { Soil depth: } \\
(\mathbf{1 0}-\mathbf{2 0} \mathbf{c m})\end{array}$ & $\begin{array}{l}\text { Soil depth: } \\
(>\mathbf{3 0} \mathbf{~ c m})\end{array}$ \\
\hline Soil pH & Alkaline & Alkaline & Alkaline \\
OM (\%) & Moderate & Low & Low \\
N (\%) & High & Medium & Low \\
Phosphorus & Low & Low & Low \\
Potassium & Low & Low & Low \\
Calcium & High & High & High \\
Boron & Low & Low & Low \\
Zinc & Low & Low & Low \\
\hline
\end{tabular}

Fruiting-yield on the basis of types of planting material

Fruiting yields of Sajiwan varied according to the types of planting materials (seedlings and branch cuttings). The maximum number of fruits in the plants originated from the seedlings was found to be 312 whereas it was 357 in those originated from the branch cuttings (Table 2). Similarly, the mean number of fruits of the plants established using branch-cuttings was 46 fruits per tree whereas that of the plants established using seedlings was 28 per tree; the pooled average yield of fruits per plant being 36 . The variation of the fruiting yields in the plants originated from branch cuttings was 1.6 times higher than that of the seedling-originated plants. This may be due to the fact that the plants propagated from stemcuttings established quickly and start producing fruits faster (Heller, 1996; Gosh and Singh, 2010). The plants propagated from stem-cuttings are also more competitive for nutrients, because they have more lateral roots than those from the plants originated from seeds (Heller, 1996). Kochhar and Kochar (2008) also observed that the plants propagated from stem-cuttings were able to grow faster and produce more fruits in the first year as compared to the ones propagated from seeds, which is in line with the findings of this study.

Prajapati and Prajapati (2005) found that fruitingyield of Sajiwan per tree ranged from $1.2 \mathrm{~kg}$ under rain-fed condition to $3.2 \mathrm{~kg}$ under irrigated condition. Similarly, a study conducted in Florida estimated as $25-42$ pounds (11-19 kg) of seeds per shrub per year (Beckford, 2008), but the yield of present study $(0-0.85 \mathrm{~kg}$; calculated from table 2 where 1 fruit $=3$ seeds, and oven dry weight of a seed $=0.79$ gram which was obtained from the measurement of this study) was found to be too low as compared to the above mentioned studies. The reason could be due to the effect of less availability of water and nutrients (Achten et al., 2010; Laviola and Dias, 2008; Yong et al., 2010; Abdrabbo et al., 2009), un-adapted provenances (Heller, 1996; Tewari et al., 2007) and other site factors viz. soil conditions, altitude, sunlight and temperature (Ghosh et al., 2007; Openshaw, 2000).

\section{Fruiting-yield in the plants originated from seedlings}

The mean number of fruits of the plants yield in the control plot was 21. Similarly, the mean number 
Table 2: Fruiting-yield on the basis of the types of planting material

\begin{tabular}{lcccc}
\hline \multirow{2}{*}{ Types of plants } & Total no. of & \multicolumn{3}{c}{ No. of fruits/plant } \\
\cline { 3 - 5 } & plants & Min & Max & Average \\
\hline Originated from seedlings & 220 & 0 & 312 & 28 \\
Originated from branch-cuttings & 172 & 0 & 357 & 46 \\
\hline
\end{tabular}

of fruits with the application of compost and chemical fertilizer were 29 and 34 respectively (Fig. 1). This indicates that the mean fruitingyield was increased by $38 \%$ with the application of compost and by $62 \%$ with the application of chemical fertilizers; however, statistically there was no significant difference in the mean fruiting-yield with the application of compost and chemical fertilizers (Fig. 1). The duration of our study might not be enough to get significant difference in the annual fruit-production per tree grown from the seedlings as the seedlings take longer time to get mature (Heller, 1996; Gosh and Singh, 2010) and also less competitive for nutrients (Heller, 1996).

\section{Fruiting-yield in the plants originated from branch cuttings}

The mean number of fruits of the plants developed from branch-cuttings in control, compost and chemical fertilizer used plots were 34, 43 and 65 respectively (Fig. 1). This shows that the mean fruiting-yield was increased by $26 \%$ with the application of compost and by $91 \%$

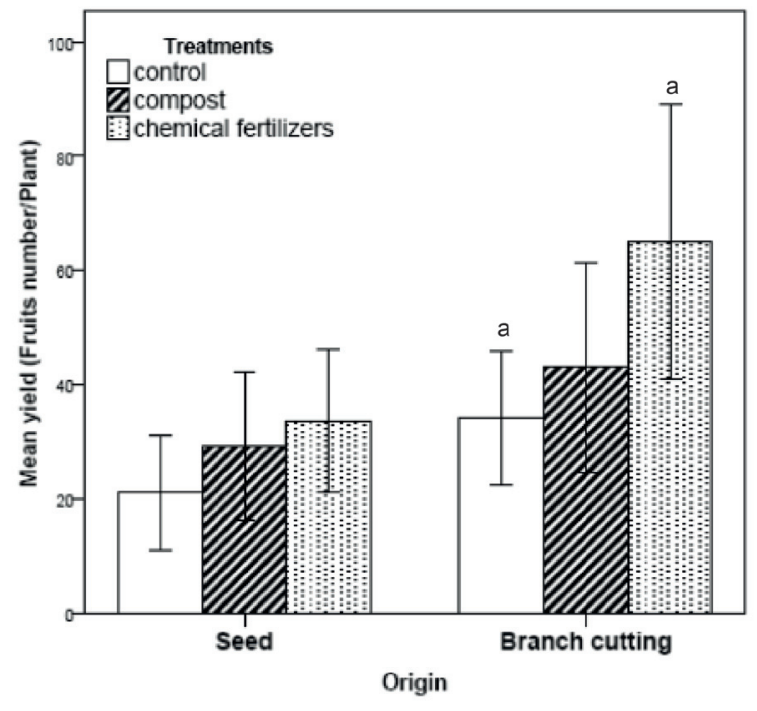

Error bars: $95 \%$ Confidence interval

Fig. 1. Fruiting-yield in the plants originated from seeds and branch cuttings with different treatments. Errors bars correspond to $\mathbf{9 5 \%}$ level of confidence intervals. The letter ' $a$ ' indicates significant differences $(p<0.01)$ according to multiple comparison LSD test. with the application of chemical fertilizers. The statistical test showed the significant difference in mean yield. While performing the multiple comparisons (LSD), only the average fruitingyields of treatment pairs i.e. control and chemical fertilizer treatments differed significantly (Fig.1). This may be due to the fact that chemical fertilizers are soluble and immediately available to the plants. Therefore, the effect of chemical fertilizer is usually direct and fast. There is a surprising evidence that fruiting-yield of Sajiwan can even be increased by 330\% (3.3 fold) with the use of 6-benzyladenine (160 ml/lit) (Bang and Zeng, 2011).

\section{Conclusion}

The research concludes that the fruiting-yield of Sajiwan in the study area was very low, and varied with the mode of regeneration. Fruitingyield in the plants originated from seedlings did not vary significantly even with the treatments they received, but it differed significantly with the application of chemical fertilizers in the plants established from branch-cuttings. This may be due to the fact that plants established from seedlings takes more time to get maturity than the plants established from branch cuttings. Therefore, caution must be provided when the result is generalized.

\section{Acknowledgements}

The authors are thankful to the Community Based Natural Forest and Tree Management in the Himalayas (ComForm) Project, IOF, Pokhara for providing financial support to conduct the study. Local employees of Khairenitar VDC of Tanahun District deserve special thanks for their help during the research period.

\section{References}

Abdrabbo, A., Abou, K. and Nahed, M. M. A. 2009. Response of Jatropha curcas L. to water deficits: Yield, water uses efficiency and oilseed characteristics. Biomass and Bioenergy 33 (10): 1343-1350. 
Achten, W. M. J., Maes, W. H., Reubens, B., Mathijs, E., Singh, V. P. and Verchot, L. 2010. Biomass production and allocation in Jatropha curcas L. seedling under different levels of drought stress. Biomass and Bioenergy 34 (5): 667-676.

Bang, Z. P. and Zeng, F. X. 2011. Benzyladenine treatment significantly increases the seed yield of the biofuel plant Jatropha curcas. Journal of plant Growth Regulation 30:166174.

Beckford, R. 2008. Jatropha curcas From Potential to Kinetic Energy. University of Florida, USA.

Forson, F. K., Oduro, E. K. and Donkoh, E. H. 2004. Performance of Jatropha oil blends in a diesel engine. Renewable Energy 29 (7): $1135-1145$.

Ghosh, A., Chaudhary, D. R., Reddy, M. P., Rao, S. N., Chikara, J. and Pandya, J. B. 2007. Prospects for Jatropha methyl ester (biodiesel) in India. International Journal of Environmental Studies 64 (6): 659-674.

Ghosh, A., Chikara, J. and Chaudhary, D. R. 2011. Diminution of economic yield as affected by pruning and chemical manipulation of Jatropha curcas L. Biomass and Bioenergy 35 (3): 1021-1029.

Gosh, L. and Singh, L. 2010. Study of factors influencing vegetative propagation of Jatropha curcas. Indian Forester 136: 1637-1648.

Gubitz, G. M., Mittelbach, M. and Trabi, M. 1999. Exploitation of the tropical oil seed plant Jatropha curcas L. Bioresource Technology 67 (1): 73-82.

Heller, J. 1996. Physic nut - Jatropha curcas L. - Promoting the conservation and use of underutilized and neglected crops. Ph.D. Thesis, Institute of Plant Genetic and Crop Plant Research, Gatersleben, Germany and International Plant Genetic Resource Institute, Rome, Italy.

Katwal, R. P. S. and Soni, P. L. 2003. Biofuels: an opportunity for socioeconomic development and cleaner environment. Indian Forester 129 (8): 939-949.

Kochhar, S., Sing, S. P. and Kochar, V. P. 2008. Effect of auxins and associated biochemical changes during clonal propagation of the biofuel plant - Jatropha curcas. Biomass and Bioenergy 32 (12): 1136-1143.

Laviola, B. G. and Dias, L. A. A. 2008. Nutrients concentration in Jatropha curcas L. leaves and fruits and estimated extraction at harvest. Revista Brasileira de Ciencias do Solo 32: 1969-1975.

Martinez-Herrera, J., Siddhuraju, P., Francis, G., Davila-Ortız, G. and Becker, K. 2006. Chemical composition, toxic/antimetabolic constituents, and effects of different treatments on their levels, in four provenances of Jatropha curcas L. from Mexico. Food Chemistry 96 (1): 80-89.

Openshaw, K. 2000. A review of Jatropha curcas: an oil plant of unfulfilled promise. Biomass and Bioenergy 19 (1): 1-15.

Parajuli, A. B. 2010. Scope of Managing Jatropha curcas and its Impacts on Rural Livelihood in Vicinity of Khairenitar VDC in Tanahun District, Nepal. B.Sc. Thesis, Tribhuwan University, Institute of Forestry, Pokhara, Nepal.

Prajapati, N. D. and Prajapati, T. 2005. A Hand Book of Jatropha curcas Linn. (Physic nut). Asian Medical Plant and Health Care Trust, Jodhpur, India.

Pramanik, K. 2003. Properties and use of Jatropha curcas oil and diesel fuel blends in compression ignition engine. Renewable Energy 28 (2): 239-248.

Ranabhat, R. 2009. Potentiality of Jatropha curcas Cultivation in Community Forest in Madanpokhara VDC in Palpa District, Nepal. B.Sc. Thesis, Tribhuwan University, Institute of Forestry, Pokhara, Nepal.

Sirisomboona, P., Kitchaiyab, P., Pholphoa, T. and Mahuttanyavanitcha, W. 2007. Physical and mechanical properties of Jatropha curcas L. fruits, nuts and kernels. Biosystems engineering 97 (2): 201-207.

Tewari, J. P., Dwivedi, H.D., Pathak, M. and Srivastasa, S.K. 2007. Incidence of a mosaic disease in Jatropha curcas Lin. From Eastern Uttar Pradesh. Current Science 93: 1048-1049.

Yong, J., Ng, Y., Tan, S. and Chew, A. 2010. Effect of fertilizer application on photosynthesis and oil yield of Jatropha curcas L. Photosynthetica 48 (2): 208-218. 